\title{
Letters
}

Website: www.bmj.com

Email: letters@bmj.com

\section{Ductal carcinoma in situ of the breast}

\section{Has author carried out an audit?}

EDITOR-We were interested in Silverstein's review on ductal carcinoma in situ. ${ }^{1} \mathrm{He}$ states that he performs mammography every 6 months on the ipsilateral breast and every year on the contralateral breast. Has he been able to audit the usefulness of this practice-namely, how many times has the mammogram predated the development of clinical recurrence?

H M Bishop Breast surgeon

M G Wallis Consultant radiologist

George Eliot Hospital NHS Trust, Nuneaton CV10 7DJ

1 Silverstein MJ. Ductal carcinoma in situ of the breast. BMJ 1998;317:734-9. (12 September.)

\section{Author's reply}

EDITOR-I thank Bishop and Wallis for inquiring about the value of ipsilateral mammography every 6 months in patients with ductal carcinoma in situ treated with breast preservation. To my knowledge there are no prospective randomised data in the medical literature that prove the value of such frequent mammography. In the early 1980 s, however, despite the lack of data, we simply made this our policy. The rationale was straightforward. If we were performing mammography yearly for healthy women why not perform it more frequently for patients with conservatively treated ductal carcinoma in situ?

Through 1998, we treated 480 patients with ductal carcinoma in situ with breast preservation (216 with excision plus radiation therapy and 264 with excision alone). Overall, 76 local recurrences occurred, 60 $(79 \%)$ of which were non-palpable and detected by mammography alone. Sixteen (21\%) local recurrences were detected by palpation; of these, $12(75 \%)$ were also detected by mammography at the time of clinical presentation. The table compares the two groups at the time of recurrence.

The median follow up from the time of original diagnosis was about 9 years for each group. Non-palpable recurrences were detected on average about 3 years earlier than palpable recurrences. In patients with non-palpable recurrences there was a $37 \%$ chance that their lesions had progressed to invasive carcinoma compared with $81 \%$ in patients with palpable recurrences $(\mathrm{P}=0.003)$. The median size of an invasive recurrence was almost $30 \mathrm{~mm}$ larger than that of a non-invasive recurrence. Distant metastases developed in two patients with non-palpable invasive recurrences and three patients with palpable invasive recurrences $(\mathrm{P}=0.03)$. The difference was significant because there were many more patients in the non-palpable group. Four deaths occurred-two in each group.

An analysis of the initial patient demographics and tumour factors, including patient age, size of original lesion, margin status, comedonecrosis, classification, nuclear grade, palpability, mammographic presentation of original lesion, and percentage of patients receiving radiation therapy, showed no significant differences between the two groups.

Although these data were collected prospectively over a long period of time, they are not randomised and do not prove the superiority of mammography every 6 months. They do, however, suggest that nonpalpable recurrences are more favourable than palpable recurrences.

Melvin J Silverstein Professor of surgery University of Southern California School of Medicine, Norris Cancer Center, Los Angeles, CA 90033, USA

Details of patients with recurrence of ductal carcinoma in situ. Values are number (percentage) unless stated otherwise

\begin{tabular}{lccc} 
Variable & Non-palpable recurrence & Palpable recurrence & P value \\
\hline Number of patients & 60 & 16 & - \\
\hline Median follow up (years) & 8.9 & 9.2 & 0.22 \\
\hline Median time to local recurrence (years) & 2.3 & 5.1 & 0.0002 \\
\hline No of invasive local recurrences & $22(37)$ & $13(81)$ & 0.003 \\
\hline Median size of local recurrence $(\mathrm{mm})$ & 19 & 49 & 0.0001 \\
\hline Stage $\geqslant 2$ at time of invasive local recurrence & $9 / 22(45)$ & $7 / 13(54)$ & 0.46 \\
\hline Local recurrence found by mammography (\%) & $60(100)$ & $12(75)$ & - \\
\hline Local recurrence found by palpation (\%) & 0 & $16(100)$ & - \\
\hline No of patients with distant metastases & 2 & 3 & 0.03 \\
\hline No of deaths from breast cancer & 2 & 2 & 0.14
\end{tabular}

\section{Selection to medical school in Great Britain}

\author{
Admissions procedure at $\mathrm{St}$ Andrews is \\ driven by purely academic criteria
}

EDITOR-Readers of McManus's paper might be misled into believing that, in 1997, it would have been unwise for a prospective medical student from an ethnic minority to apply to St Andrews. ${ }^{1}$ The reality is that for those who met, or were predicted to meet, our clearly published academic entry requirements, the chance of receiving an offer was $98.5 \%$ (compared with $97 \%$ for comparably qualified white applicants). It is doubtful whether these offer rates were equalled by any other medical school in the United Kingdom.

The difference between perception and reality can be explained as follows. First, McManus based his calculations on achieved A level or Highers grades whereas, for the former at least, selection to medical school has to be based largely on predicted grades. At St Andrews, and probably elsewhere, the relationship between predicted grades and likelihood of an offer is far from linear but shows a marked threshold effect, offer rate below the threshold being effectively zero. Second, for those applicants attempting to achieve the required entry grades at a

\section{Advice to authors}

We prefer to receive all responses electronically, sent either directly to our website or to the editorial office as email or on a disk. Processing your letter will be delayed unless it arrives in an electronic form.

We are now posting all direct submissions to our website within 72 hours of receipt and our intention is to post all other electronic submissions there as well. All responses will be eligible for publication in the paper journal.

Responses should be under 400 words and relate to articles published in the preceding month. They should include $\leqslant 5$ references, in the Vancouver style, including one to the BMJ article to which they relate. We welcome illustrations.

Please supply each author's current appointment and full address, and a phone or fax number or email address for the corresponding author. We ask authors to declare any competing interest. Please send a stamped addressed envelope if you would like to know whether your letter has been accepted or rejected.

Letters will be edited and may be shortened.

www.bmj.com

letters@bmj.com 
second or third sitting, we take account of achieved grades at previous sittings and at GCSE, which were not included in McManus's dataset.

There are other deficiencies in McManus's approach. It may, however, be sufficient to note that fewer than $50 \%$ of candidates from ethnic minorities met our academic threshold (compared with over $70 \%$ of whites), that ethnic minority applicants who were resitting had correspondingly weaker academic credentials when GCSE and first sitting A level results were assessed, and that, overall, the simple odds ratio for receiving an offer from St Andrews (ethnic minority versus white applicants) corresponds exactly to the odds ratio for meeting our academic entry requirements.

Although the number of applicants from different subgroups taking up places in particular medical schools measures student choice as well as the schools' selection procedures, it may be worth recording that the proportion of St Andrews entrants in 1997 who were from ethnic minorities exactly matched the proportion who applied.

The difficulties inherent in digesting and analysing limited and incomplete data are properly emphasised by McManus but, given that this is by no means the first publication to address the issue of equity in selection for places at medical school, it is unfortunate that more time was not taken to analyse other evidence and draw more reliable conclusions. The important point to remember is that the evidence clearly confirms that the University of St Andrews' approach to applications is driven by purely academic criteria.

C. Michael Steel Professor in medical science David Jackson Admissions officer medical science David W Sinclair Prodean medical science Stephen R Magee Director of admissions University of St Andrews, School of Biomedical Sciences, St Andrews, Fife KY16 9TS

1 McManus IC. Factors affecting likelihood of applicants being offered a place in medical schools in the United Kingdom in 1996 and 1997: retrospective study [with commentaries by A Esmail and M Demetriou]. BMI 1998:317:1111-7. (24 October)

\section{Dundee University Medical School has some questions}

EDITOR-McManus's study on factors affecting admission to medical schools ${ }^{1}$ seems to contain discrepancies in the data that are misleading-namely, in table 2 and its comparison with figure 3 , which deals with the possible deleterious effect of ethnic origin on admission to medical schools. In the table, Dundee University Medical School is "black spotted" and the results are described as "combined" from the 1996 and 1997 data from the Universities and Colleges Admissions Service.

Although it is not clear how such a combination of data has been achieved it would be reasonable to assume that the mean odds ratios from figure 3 have been used. If this assumption is correct we reason that an error may have occurred. The mean odds ratio for Dundee is 1.80 , and this is awarded the "black spot" in table 2. However, Aberdeen (1.85), Belfast (4.0), Oxford (2.15), and Glasgow (2.0) all have greater mean odds ratios but are shown in table 2 as free from ethnic minority bias. McManus needs to address this paradox or explain the derivation of the data in table 2 in more detail. If such an error exists, the validity of the whole content of table 2 has to be questioned. Given that the table has been recommended to applicants and their advisers in schools and colleges as a guide to where it is best to apply, the consequences are serious. We are confident that our own admissions policy is fair. Our internal audit of 1997 applications using predicted examination data and personal achievement scores for all applicants shows an odds ratio of 1.12 for "whites" versus "ethnic minorities." It seems that, contrary to what is shown in McManus's table 2, applicants from ethnic minorities would be well advised to consider applying to Dundee.

Figure 1 seems to indicate that ethnic minorities are disadvantaged in respect of offers made. The data in the figure are, however, based on actual examination results and not the predictions that most of us use when making our offers. We, like our colleagues in St Andrews, ${ }^{2}$ find that a higher proportion of people from ethnic minorities are rejected because of poor predictions than is the case for "whites." There may be a disadvantage, but it is not of the making of the medical schools. Excluding Highers from the analysis is also inappropriate, and we have many reservations about the validity of the McManus paper in respect of Scottish medical schools. An independent analysis for Scotland is needed. Candidates from ethnic minorities should, however, not be deterred from applying to Dundee.

D A Levison Dean

D Parratt Convenor of medical admissions

University of Dundee Medical School, Ninewells Hospital and Medical School, Dundee DD1 9SY davidp@dth.scot.nhs.uk

1 McManus IC. Factors affecting likelihood of applicant being offered a place in medical schools in the United Kingdom in 1996 and 1997: retrospective study, BM 1998:317:1111-6. (24 October.)

2 Steel CM, Jackson D, Sinclair DW, Magee SR. Paper is misleading about St Andrew's. 1998. www.bmj.com/cgi/ eletters/317/7166/1111.

\section{Prejudice may not be responsible for} difference in success rates

EdiTor-Several omissions in McManus's analysis about selection of students for medical school may be no fault of the author but invalidate the research. ${ }^{1}$ GCSE grades and predicted A level grades were not included. These are among the main factors that influence selection for interview at St George's Hospital Medical School and no doubt elsewhere. This is rather like trying to investigate the causes of stroke without taking blood pressure or cigarette smoking into account. In a past analysis of applications to St George's (1988-90) there was a clear difference in $\mathrm{O}$ level scores between European (mean 21 points, $\mathrm{n}=1882$ ) and Asian (mean 19 points, $\mathrm{n}=845$ ) applicants without A levels, for whom $\mathrm{O}$ level results would be the main indicator of academic attainment.

These are not representative samples of the ethnic groups. The proportion of university applicants applying for medicine is much greater among applicants from ethnic minorities than among European applicants. We thus may not be comparing like with like. We are not dealing with representative samples of Europeans and Asians here, but with the extreme upper tails of the distribution of academic attainment. The greater proportion of applicants for medicine from ethnic minorities may imply that this group of applicants contains more comparatively weak applicants than the European group. The O level scores described above support this view.

Do the adjusting variables explain any of the differences between ethnic groups? McManus mentions many variables that do not explain the difference in offers by ethnicity, but he does not show us whether the different ethnic groups differ in these variables. Only the adjusted odds ratio is given, without the unadjusted odds ratio with which it could be compared.

There is no frame of reference. Does this phenomenon apply to medical schools only, to the universities as a whole, or to other sectors with high applications per place, such as Oxbridge, old universities, other high demand subjects? The analysis applies only to applicants in medicine. It seems unlikely that staff concerned with admissions to medical schools are universally racially prejudiced while those in other university sectors are not

We should also admit that everybody is prejudiced, including ourselves. The language of this paper, which refers consistently to the "disadvantage" experienced by applicants from ethnic minorities, prejudges the issue, for example. In every walk of life, we should guard against prejudice, but we should not assume that a difference in success rate is in itself evidence that this is the explanation.

J M Bland Professor of medical statistic St George's Hospital Medical School, London SW17 0QT

Email:mbland@sghms.ac.uk

1 McManus IC. Factors affecting likelihood of applicant being offered a place in medical schools in the United Kingdom in 1996 and 1997: retrospective study [with commentaries by A Esmail and M Demetriou]. BMJ 1998;317:1111-7. (24 October.)

\section{League tables only help if uncertainty is properly looked at}

EDITOR-The article by McManus on selection to medical schools in Britain ${ }^{1}$ gives a correlation in the order of 0.5 -between a medical school's disadvantaging of ethnic minority applicants in consecutive yearswhich is not of itself evidence that there is structural racism, as Esmail thinks, ${ }^{1}$ or that there are meaningful differences in success rates at in vitro fertilisation clinics. ${ }^{2}$ Indeed, having ordered medical schools by their 1997 performance, McManus's figure 3 clearly shows classical regression to the mean ${ }^{1}$; there was a tendency for low disadvantage 
schools in 1997 to have higher estimated disadvantage in 1996, whereas high ranked disadvantage schools in 1997 tended to have lower estimated disadvantage in 1996.

There may be other empirical evidence of individual medical schools' "structural racism," such as important heterogeneity between medical schools in their disadvantaging of applicants from ethnic minorities, and this may be consistent between calendar years. But such evidence was not presented in McManus's paper. For example, Esmail condemned so-called "persistent offenders" among medical schools. ${ }^{1}$ "Persistent offender" might mean: consistency between years of effect size (how greatly a medical school disadvantages ethnic minorities); or of its ranking between years. Esmail ignores the uncertainties in estimating annual disadvantage per medical school, ${ }^{3}$ which are shown in McManus's figure 3. That there is overall disadvantaging of ethnic minority applicants is the primary message. Esmail seeks to delve deeper into heterogeneity between schools, but a full analysis on that issue was not given.

League tables do not help if glibly or popularly interpreted, as schools, ${ }^{4}$ hospitals, and prisons know to their cost. The new data should be an impetus for change across medical schools. Indictment of individual medical schools goes beyond the published data and underlines the fact that league tables can be more hindrance than help.

Sheila M Gore Senior statistician

Medical Research Council Biostatistics Unit, Cambridge CB2 2SR

1 McManus IC. Factors affecting likelihood of applicants being offered a place in medical schools in the United Kingdom in 1996 and 1997: retrospective study [with commentaries by A Esmail and $\mathrm{M}$ Demetriou]. BMJ 1998;317:1111-7. (24 October.)

2 Marshall EC, Spiegelhalter DJ. Reliability of league tables of in vitro fertilisation clinics: retrospective analysis of live birth rates. BMJ 1998;316:1701-4.

3 Sanderson C, McKee M. Commentary: how robust are rankings? The implications of confidence intervals. $B M$ 1998;316:1705.

4 Goldstein H, Spiegelhalter DJ. Statistical aspects of institutional performance: league tables and their limitations (with discussion).JR Stat Soc 1996;159:385-444. (Series A.)

\section{Author's reply}

EDITOR-Steel et al discuss the deficiencies of my analysis and say that at St Andrews in 1997, applicants from ethnic minorities who met the school's entry requirements had a $98.5 \%$ chance of receiving an offer, compared with $97 \%$ for comparably qualified white applicants. Data cited by Steel elsewhere claimed, "Of the 452 eligible white applicants [for entry in 1997], offers were made to $428(94.7 \%)$ while offers were made to 77 of the 87 eligible ethnic minority candidates $(88.5 \%)$ )" (personal communication). The relative risk of rejection for minority candidates seems to be $2.17(11.5 \% \mathrm{v}$ $\left.5.3 \% ; \chi^{2}=4.72, \mathrm{df}=1, \mathrm{P}=030\right)$, with an odds ratio of 2.31 (95\% confidence interval 1.06 to 5.04), which is similar to my own estimate. These data were calculated "by hand," based on predicted and achieved grades, and only considered candidates achieving the academic threshold with selection strongly weighted towards academic performance.
The poorer outcome of ethnic minority applicants therefore requires proper explanation, rather than empty reassurances.

Levison and Parratt claim that my methodology is flawed. There is no paradox or error; Dundee met the criteria for significance, whereas Aberdeen, Oxford, and Glasgow did not. Nor was it reasonable to assume that the mean odds ratios were used since my paper clearly said otherwise.

Bland refers to the omission of GCSE and predicted A level grades. They would have helped interpretation but had not been collected electronically, and deans of medical schools in the United Kingdom agreed to proceed in their absence. They were, however, available in our 1991 cohort, ${ }^{1}$ which resulted in similar findings to those in 1996 and 1997. By citing 1988-90 data, Bland acknowledges that previous studies help in interpreting the 1996 and 1997 data-despite critical claims that everything has changed since 1991 (albeit without numerical evidence).

Bland also comments on the frame of reference. Since I analysed applications to medical school in 1996 and 1997, I made no claims about universities as a whole or other sectors. Modood and Shiner's broader study of university applicants in 1992 did, however, find similar effects. ${ }^{2}$ The remark, "It seems unlikely that staff concerned with admissions to medical school are universally racially prejudiced while those in the other university sectors are not," relates to nothing in my paper. Bland's idiosyncratic quasipostmodernist analysis of the word "prejudice" I suggest as an exercise for those interested in discourse analysis and narrative based medicine.

With reference to Gore's carefully balanced thoughts, league tables can have an uncomfortable degree of uncertainty, and the separate results for 1996 and 1997 allow an estimate of the problem. I hope that I did not "indict" individual medical schools (and previously have anonymised schools $)^{1}$. Naming was inevitable given the Council of Heads of Medical Schools' release of identified data, a decision which presumably took possible misinterpretation into consideration.

Chris McManus Professor of psychology and medical education

Royal Free and University College School of Medicine, Whittington Hospital, London N19 5NF

1 McManus IC, Richards P, Winder BC, Sproston KA, Style $\mathrm{V}$. Medical school applicants from ethnic minorities: identifying if and when they are disadvantaged. $B M$ 1995;310:496-500.

2 Modood T, Shiner M. Ethnic minorities and higher education: why are there differential rates of entry? London: Policy Studies Institute, 1994

\section{Vitamin A for treating shigellosis}

\section{Study did not prove benefit}

EDitor-Hossain et al conclude that vitamin A along with standard antibiotic reduces the severity of acute shigellosis and that vitamin A supplementation should be added to the standard treatment for acute shigellosis. ${ }^{1} \mathrm{We}$ disagree with those conclusions.
The benefit of vitamin A as adjuvant treatment for shigellosis can be judged only in a study in which patients receive adequate antimicrobial treatment. ${ }^{2}$ In Hossain et al's study $64 \%$ of patients were infected with strains of shigella resistant to nalidixic acid, which was used to treat study patients. It is unclear how many patients were given an alternative effective antibiotic or when treatment was changed.

The inadequacy of antimicrobial treatment in this study is reflected in clinical cure rates of less than $50 \%$ in patients who did and did not receive vitamin A supplements. That is not acceptable as adequate antimicrobial treatment routinely achieves a cure rate of $65 \%$ or more. ${ }^{34}$ Indeed, Hossain and colleagues calculated their sample size based on a $98 \%$ cure rate in the vitamin A group.

Their definition of cure included the absence of mucus or blood in stools. These measures are not good indicators of overall clinical status and are subject to variation between observers. It is important to know which component of the definition of clinical cure (three or fewer formed stools, no visible stool blood or mucus, afebrile) used in the study accounted for the difference in cure rates between groups and if there were any differences in more objective outcome measures, such as total number of stools during the study or duration of fever. ${ }^{35}$

The authors contend that the differences in reported outcome between groups may have been because vitamin A supplementation stimulated phagocytosis and cell mediated killing of pathogens. The similar rate of clearance of shigella observed in the two groups seems to contradict this contention. The rapid divergence (by 24 hours) between groups in the proportion of patients with clinical cure suggests a more rapid response than could reasonably be expected to be achieved by vitamin A "enhanced repair of the micro-ulcers in the gut epithelium."

Vitamin A has an important role in public health in developing countries. The rationale for its use, however, must come from well conducted studies in which children receive effective primary treatment for their illness (in this case effective antibiotics), and for which there are clear, reproducible, and clinically relevant definitions of treatment outcome.

Mohammed Abdus Salam Chief physician

Wasif Ali Khan Physician

Ujjwal Dhar Physician

International Centre for Diarrhoeal Disease

Research, Bangladesh, GPO Box 128, Dhaka 1000, Bangladesh

Anne Ronan Paediatrician

Child and Family Health Services, Wallsend Campus, Newcastle, New South Wales, Australia

Nigel C Rollins Consultant

Department of Paediatrics and Child Health, University Natal, Private Bag 7, Congella 4013, South Africa

Michael L Bennish Associate professor Division of Geographic Medicine and Infectious Diseases, New England Medical Center, Tufts University School of Medicine, Boston, MA, United States 
1 Hossain S, Biswas R, Kabir I, Sarker S, Dibley M, Fuchs G, et al. Single-dose vitamin A treatment in acute shigellosis in Bangladeshi children: randomised double blind controlled trial. BMJ 1998;316:422-6.

2 Salam MA, Bennish ML. Antimicrobial therapy of shigellosis. Rev Infect Dis 1991;13(suppl 4):S332-41.

3 Salam MA, Bennish ML. Therapy for shigellosis. I Randomised, double blind trial of nalidixic acid in childhood shigellosis. J Pediatr 1988;113:901-7.

4 Salam MA, Dhar U, Khan WA, Bennish ML. Randomised comparison of ciprofloxacin suspension and pivmecillinam for childhood shigellosis. Lancet 1998:352.529-7.

5 Salam MA, Seas C, Khan WA, Bennish ML. Treatment of shigellosis. IV. Cefixime ineffective in shigellosis in adults. Ann Intern Med 1995;123:505-8.

\section{Authors' reply}

EDITOR-Alternative effective antibiotics were given to $65 \%(54 / 83)$ of children in our study: $63 \%(26 / 41)$ in the placebo group and $67 \%(28 / 42)$ in the vitamin A group. All had Shigella dysenteriae type 1 strains. After the organism was identified by culture, the antibiotic was changed to pivmecillinam within 48 hours because of the known sensitivity pattern of the organism in our hospital.

All children with nalidixic acid sensitive shigella ( $S$ flexneri or $S$ boydii) in the vitamin A group were cured by day 5 compared with $53 \%$ in the placebo group. For subjects with nalidixic acid resistant shigella, 17\% (5/28) in the vitamin A group and none in the placebo group were cured by day 5 .

Children were defined as clinically cured if they passed three or fewer formed stools in a day without any visible blood and mucus, were afebrile, and had no abdominal pain or tenderness on that day. We observed a difference in clinical cure between the groups after 48 hours, not rapid divergence by 24 hours. Stool outcomes were the main determinants of clinical cure (table). Salam et al's definitions of clinical cure as "no bloody mucoid stools, six or fewer total stools, and no fever" and failure as "more than nine stools or more than two watery stools, or were afebrile" are more arbitrary than ours. ${ }^{2}$ Although there is no universally accepted definition of clinical cure in shigellosis, we believe our definition is more relevant and practical within the context of clinical care. Research staff at the International Centre for Diarrhoeal Diseases Research, Bangladesh, are well acquainted with stool consistencies, blood, and mucus. To minimise interobserver variation, we standardised study nurses' assessment of outcome measures and doctors arbitrated on any uncertainty. Moreover, a double blind randomised trial provides little scope for such bias to determine the outcome.

Evaluation of the individual severity symptom of placebo and vitamin A group on study day 5

\begin{tabular}{|c|c|c|c|c|}
\hline Variables & $\begin{array}{c}\text { No }(\%) \text { on } \\
\text { placebo } \\
(n=41)\end{array}$ & $\begin{array}{c}\text { No }(\%) \text { on } \\
\text { vitamin } A \\
(n=42)\end{array}$ & $\chi^{2}(\mathrm{P}$ value $)$ & $\begin{array}{l}\text { Risk ratio } \\
(95 \% \mathrm{CI})\end{array}$ \\
\hline No fever & $38(93)$ & $39(93)$ & $0.15(1.0)$ & $0.98(0.21-4.56)$ \\
\hline No abdominal pain or tenderness & $30(73)$ & $35(83)$ & $0.73(0.39)$ & $0.62(0.27-1.45)$ \\
\hline No blood or mucus in stool & $19(46)$ & $24(57)$ & $0.59(0.44)$ & $0.80(0.51-1.25)$ \\
\hline $\begin{array}{l}\leqslant 3 \text { stools (irrespective of consistency or presence of blood or } \\
\text { mucus) }\end{array}$ & $15(37)$ & $25(60)$ & $4.32(0.03)$ & $0.64(0.41-0.99)$ \\
\hline Formed stool (irrespective of presence of blood or mucus) & $12(29)$ & $22(52)$ & $4.53(0.03)$ & $0.67(0.46-0.98)$ \\
\hline Clinical cure* ${ }^{*}$ & $8(19)$ & $19(45)$ & $5.14(0.02)$ & $0.68(0.50-0.93)$ \\
\hline
\end{tabular}

*According to definition
The cellular and tissue response to a large dose of oral vitamin A can be measured in hours and a few days. ${ }^{3}$ Vitamin A might similarly be predicted to act rapidly on colonic immune and mucosal function and integrity. The rapid effect of vitamin A in diarrhoea related to measles also suggests fundamental and rapidly reversible host mechanisms that cope with established systemic infection, ${ }^{4}$ although it is unclear whether the effect is due to adjuvant properties or nutritional activity, or both. Strong evidence exists on the effect of vitamin A on cell mediated immunity and on the synthesis and secretion of cytokines. ${ }^{5}$ Excretion of viable organisms in the stool does not necessarily reflect events in intracellular colonic tissue and by itself does not refute the possibility of vitamin A enhanced immune activity against shigella.

Shahadat Hossain Senior medical officer

Rabi Biswas Research physician

Iqbal Kabir Scientist

Shafique Sarker Associate scientist

George Fuchs Interim director

International Centre for Diarrhoeal Disease

Research, Bangladesh, GPO Box 128, Dhaka 1000 , Bangladesh

Dilip Mahalanabis Director, Society for Applied Studies

108 Maniktola Main Road, Flat 3/21, Calcutta 700054 , India

Michael Dibley Senior lecturer

Centre for Clinical Epidemiology and Biostatistics, University of Newcastle, NSW 2308, Australia

1 Salam MA, Dhar U, Khan WA, Bennish ML. Randomised comparison of ciprofloxacin suspension and pivmecillinam for childhood shigellosis. Lancet 1998:352:522-7.

2 Bennish ML, Salam MA, Khan WA, Khan AM. Treatmen floxacin with standard 5-day therapy. Ann Intern Med 1992:117:727-34

3 Sommer A, West K. Vitamin A deficiency: health, survival and vision. Oxford: Oxford University Press, 1996.

4 Coutsoudis A, Broughton M, Coovadia HM. Vitamin A supplementation reduces measles morbidity in young African children: a randomized, placebo-controlled, double-blind trial. Am J Clin Nutr 1991;54:890-5.

5 Semba RD. The role of vitamin A and related retinoids in immune function. Nutr Rev 1998;56:S38-48.

\section{Rationing}

Politicians, not doctors, must make the decisions about rationing

EDITOR-Klein acknowledges that rationing is "inescapably a political process," yet he accepts "muddling through," albeit elegantly, as a way out of the dilemma. The practice of muddling through-for which read ad hoc decision making by unelected of shigellosis. III. Comparison of one-or-two-dose cipro- managers and doctors-is, however, far from elegant. In a paper at the conference to which Klein refers I pointed out that the present fudge has several drawbacks and that NHS managers and doctors should have nothing to do with rationing until elected politicians take firm decisions. (J N Rao, international conference on priorities in healthcare, London, October 1998).

The more successfully we contain rising demand without stoking public unrest the less is the pressure on elected politicians to reconsider the overall resources directed at health care. If politicians took the decisions they would be compelled to view them as part of a wider state policy that included taxation, spending on other services, and new ways of raising revenues.

Managers ration within an arbitrarily defined budget and according to its dictates. Managers in charge of the drug budget may deny a patient an effective treatment; meanwhile, at the same time elsewhere in the district, another budget may be spent on less worthwhile pursuits. This is inherently inefficient.

Health officials are not directly accountable to the population they are supposed to serve. Their main pressure to ration is to balance the books; their chief criterion is simply that public protest must not reach unmanageable levels. The only recourse open to aggrieved members of the public is to seek judicial review - a lengthy and expensive process. ${ }^{3}$

No agreed rational basis for rationing services exists. Klein acknowledges this Partly it is because no agreement exists about the fundamental purpose of a state funded healthcare system such as the NHS. If politicians had to decide on rationing issues they would have first to lead a debate on this most fundamental of questions.

It is a myth that muddling through is working. What has really happened is that ad hoc decisions, determined mainly by budgetary considerations, have led to widespread inequalities in access, a general decline in quality, ${ }^{4}$ and arbitrary and inefficient allocation of resources, determined mainly by the need to generate as little public disquiet as possible. Thus most managers' lists of rationed services include the same items, such as in vitro fertilisation and gender reassignment surgery.

Muddling through isn't working. Politics is about making choices. So is rationing. If elected politicians refrain from making decisions about rationing then NHS managers and doctors should not fill the vacuum.

Jammi N Rao Honorary senior lecturer Department of Public Health and Epidemiology, University of Birmingham, Birmingham B15 2T1 Jammi@bharat.demon.co.uk

1 Klein R. Puzzling out priorities. BMJ 1998;317:959-60. (10 October.)

2 Hunter D. Rationing: the case for "muddling through elegantly." BMJ 1995;311:811.

3 Weir S, Beetham D. Political power and democratic control in Britain. London: Routledge, 1998.

4 Hamon C. Some NHS care is unacceptable. BMJ 1998;317:1463. (21 November) 
Use of representative health panel shows changes in public attitudes to rationing

EDITOR-Sabin points out that patients should understand the need for priority setting if the case for it is made simply and honestly. Many of us already know, however, that there are "major and practical difficulties in engaging the public on any debate about priorities." Locally, we have successfully tried to meet this challenge of public involvement through the use of an innovative health panel, Talkback.

Talkback consists of 2000 local residents in the Calderdale and Kirklees Health Authority area (total population 580000 ). The panel was jointly established in 1994 between the health authority and the two local authorities. Its membership is representative of the age, sex, and ethnicity of the local population. The panel is surveyed three or four times each year on a range of broad issues. Members are updated regularly (through newsletters and focus groups) on action that has been taken (if any) since previous surveys.

In one survey, in 1994, questions were asked about who should be involved in the rationing of health care and what should be rationed. At the same time a high profile media campaign was conducted, with a regular series of newspaper articles and radio briefings on local health issues and priorities. The results of that survey (confirmed by more recent surveys) showed that rationing should be led by local clinicians but, importantly, that over three quarters of our panel supported the health authority's approach to priority setting. Additional comment from panel members and local community health councils allowed for the introduction of an appeals process within the "low priorities" policy launched by the health authority. Follow up surveys of panel members have confirmed previous positive support for the policy. Together with extensive local media briefing, this ensured the smooth launch and implementation of a potentially controversial policy.

The rationing of (global) health care is inevitable, but it has always been so. A framework to ration health care that has true professional and public support is essential. Local experience tells us that regular use of a representative health panel can show changes in public attitudes in ways that can contribute to effective decision making on the rationing of health care.

C Worth Director of public health

Calderdale and Kirklees Health Authority,

Huddersfield, West Yorkshire HD4 5RH

1 Sabin JE. Fairness as a problem of love and the heart: a clinician's perspective on priority setting. BMJ 1998; 317 1002-4. (10 October)

2 Royal College of Physicians of London. Setting priorities in the NHS: a framework for decision-making. London: RCP, 1995 .

Fidelity and stewardship are incompatible when attempted by same individual

EdITOR-Sabin suggests that clinicians can ethically ration their patients' care. ${ }^{1}$ Other commentators in the United States have urged British doctors to retain our tra- ditional ethical stance of doing the best possible for our individual patients. ${ }^{2}$ Experience in the United Kingdom suggests that both fidelity (caring for patients) and stewardship (rationing resources) are ethically incompatible when attempted by the same individual. Once one departs from the aim of providing the best possible care for the patient in front of you it is too easy to be influenced by prejudice. Am I depriving this patient of interferon beta because the health economics do not add up or because of his or her race, sex, social class, or appearance?

Making the clinician responsible for rationing puts too much power in one person's hands. Patients start to believe that their access to treatment depends on whether, for example, their general practitioner likes them. Having the doctor do the rationing also fundamentally undermines the doctor-patient relationship as the patients cannot be sure if the advice they are receiving is best for them as individuals or best for the wider community.

It is important that patients think that their doctor is on their side. Making doctors stewards of the public purse undermines their role as patient advocates. Fidelity and stewardship are in conflict and cannot ethically be performed by a clinician.

Simon J Ellis Consultant neurologist

Department of Neurology, North Staffordshire Royal Infirmary, Stoke on Trent ST4 7LN

1 Sabin JE. Fairness as a problem of love and the heart: a clinician's perspective on priority setting. $B M$ nician's perspective on $P$ 2 Kassirer JP. Managing care. Should we adopt a new ethic? N Engl J Med 1998;339:397-8.

Better variables than QALYs in decision making may become apparent

EDITOR-We can all rejoice if proposals for guiding decisions that allocate healthcare resources are emerging that are less crude than some of their forerunners. ${ }^{1}$ We would hope that debate and dissemination of these proposals would be free of crude rhetoric and caricature; but not yet, it seems.

Perhaps somewhere there is a health economist who claims that decisions that allocate scarce resources for health care should be made solely by selecting the services with the highest quality adjusted life years (QALYs) per unit cost attached. Or perhaps some health economist will claim that existing QALY figures are sufficiently transparent and available that no further development of them is worth investigating. More typically, and rightly, health economists would caution to the contrary in both cases.

The proponents of muddling through to allocation decisions, elegantly or otherwise, ${ }^{23}$ are either complacent or defeatist if they believe that we cannot usefully do more to establish, disseminate concisely, and use available evidence on which healthcare activities contribute reliably to improvements in health.

Few can doubt that evidence may be variably interpreted, sometimes deliberately. But why rules to guide the decision making process would be any less prone to unreasonable interpretation than rules to guide which options to pick remains unclear. Relying heavily for decision making on QALYs may be inappropriate; superior forms of information about the contributions of healthcare activity to improvements in health, or other desirable outcomes, may become apparent

Reasonable decision making about the allocation of scarce resources is not best served by writing off attempts based on something better than muddling through in ignorance until the evidence reliably confirms that we have found a superior alternative way.

Stephen Heasell Senior lecturer in economics

Nottingham Trent University, Nottingham

NG1 4BU

stephen.heasell@ntu.ac.uk

1 Holm S. Goodbye to the simple solutions: the second phase of priority setting in health care. BMJ phase of priority setting

2 Hunter DJ. Rationing: the case for "muddling through elegantly." BMJ 1995;311:811

3 Mechanic D. Muddling through elegantly. Health Affairs 1997;16:83-92.

\section{Effect on suicide rate of having reduced unemployment is uncertain}

EDITOR-Lewis and Sloggett recommend policies to reduce unemployment in order to prevent suicide. ${ }^{1}$ They show that those unemployed in 1981 were overrepresented among suicides 2-11 years later. This seems to imply that the suicides are caused by the unemployment. Their exclusion of cases up to two years after registration to "reduce selection effects" shows that they think that the consequences are long term. Selection problems can hardly be avoided or reduced here by exclusion of the cases nearest in time to registration; it just blurs the hypothesis by excluding the most obvious examples (becoming unemployed as a suicidal crisis).

Causal hypotheses may be supported by studies at the collective level since these avoid confounders at the individual level ${ }^{2}-$ for example, changes in the Swedish unemployment rate and male suicide rate correlated significantly over 1920-41. ${ }^{3}$ The effect appeared in the first year of periods of mass unemployment.

As unemployment re-emerged dramatically in Sweden in 1990, rising suicide rates were expected, but they didn't occur. These "natural experiments" show that the relation between unemployment and suicide is far from clear. The only consistent finding in Sainsbury et al's study ${ }^{4}$ and my replication of it ${ }^{5}$ was that the unemployment rate correlated significantly negatively with that of male suicide rates in both 1961-3 and 1977-9 in 18 European countries.

Recent British trends in unemployment and suicide have seemed to coincide: the male rates, especially in the younger age groups (15-24, 25-34, 35-44), correlate significantly with national unemployment rates $(r=0.46-0.83$, all $\mathrm{P}<0.025)$. When annual changes in unemployment and suicide rates are cross correlated, however, the relations disappear completely even if 


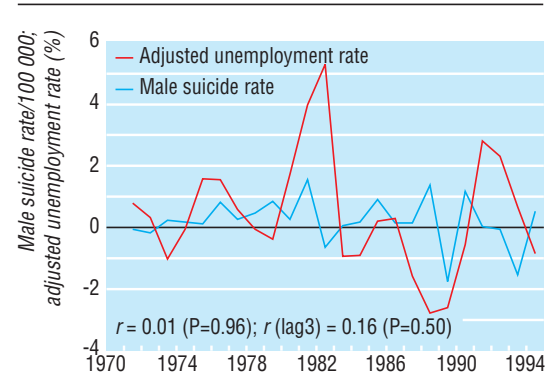

Annual changes in male suicide rate and unemployment rate, 1970-94. Adjustment compensates for change in unemployment registration in 1982 (Denman J, McDonald P. Unemployment statistics from 1881 to the present day. Labour Market Trends 1996 Jan:5-18). r=correlation between change in unemployment rate and change in male suicide rate in same year; $r(\operatorname{lag} 3)=$ correlation between change in unemployment rate in one year and change in male suicide rate three years late

we allow for lagged effects (figure). There is no indication of unemployment "causing" suicide so that increases in its level would be followed by later increases in suicide rates.

The risks in recommending reduced unemployment as a remedy for suicide are twofold: inefficiency (lacking the causal link, one might invest large resources without reducing suicide rates) and lack of focus (by paying attention to phenomena only marginally connected with the problem, we might lose the focus from more credible forms of prevention).The effects of having more jobs are uncertain, but making unemployment financially easier to bear and reducing extreme situations could be justified even from the point of view of preventing suicide.

Ilkka Henrik Mäkinen Researcher

Centre on Health of Societies in Transition,

University College of South Stockholm, Box 4101, 14104 Huddinge, Sweden

Ilkka.Makinen@sh.se

1 Lewis G, Sloggett A. Suicide, deprivation, and unemployment: record linkage study. BMJ 1998;317:1283-6. (7 November.)

2 Norström T. Deriving relative risks from aggregate data. J Epidemiol Community Health 1988;42:333-40.

3 Norström T. A time series analysis of the Swedish suicide rate 1915-1968. In: Bergryd U, Janson CG, eds. Sociological miscellany. Stockholm: Department of Sociology, Stockmiscellany. Stockholm: Depart

4 holm University, 1987:142-60. Sainsbury P,Jenkins J, Levey A. The social correlates of sui-
cide in Europe. In: Farmer R, Hirsch S, eds. The suicide syncide in Europe. In: Farmer R, Hirsch S, eds.
drome. London: Croom Helm, 1980:38-53.

5 Mäkinen IH. Are there social correlates to suicide? Soc Sci Med 1997;44:1919-29.

\section{Trials of postoperative antiemetics need three arms}

EDITOR-Tramèr et al present strong evidence that postoperative antiemetics should be tested against placebo. ${ }^{1}$ While accepting their scientific argument, and to some extent altering my previous view, ${ }^{2}$ I am none the less dismayed that it is so. The conclusion of Tramèr et al will provide support for drug companies' reluctance to test their new antiemetics against established drugs. I suggest that trials of postoperative antiemetics should always have three arms: placebo, test drug, and control drug. This design provides the internal index of sensitivity asked for by Tramèr et al, as well as the comparative data that clinicians need when they prescribe.

Tramèr et al found no support for the "widely held view that use of droperidol is limited by adverse reactions." I do not imagine that this will prevent the almost universal habit of investigators putting forward "the high incidence of serious side effects" of the older antiemetics as a rationale for their studies on ondansetron and the later 5-HT antagonists. It is an indictment of our systems of testing and their funding that, as Tramèr et al write, we still do not know the efficacy or optimal doses of the older and far less expensive antiemetics.

Neville W Goodman Consultant anaesthetist Southmead Hospital, Bristol BS10 5NB

1 Tramèr MR, Reynolds DJM, Moore RA, McQuay HJ. When placebo controlled trials are inadequate $B M J$ 1998;317:875-80. (26 September)

2 Aspinall RL Goodman NW. Denial of effective treatment and poor quality of clinical information in placebo cor cond poled tials of ond $1995,311: 844-6$

\section{Guidelines for clinical guidelines should distinguish between national and local production}

EDITOR-Jackson and Feder put forward sensible arguments for pragmatic simplicity in clinical guidelines that should be reflected in similar simplicity in guidelines for guidelines. ${ }^{1}$ However, they do not distinguish between guidelines produced by reputable national bodies and those that have been adapted from others for local use.

Nationally produced guidelines must be rigorously developed and should pass an appraisal process using criteria such as those suggested by Cluzeau et al. $^{2}$ The guidelines produced by the Scottish Intercollegiate Guideline Network are good examples of documents that have been produced with such rigour." Such nationally produced guidelines still require local adaptation to suit local circumstances and to achieve a sense of ownership by local clinicians, which is a major factor in uptake and use. ${ }^{4}$ In their local form, guidelines should probably have three components: a simple algorithm that gives a practical sequence of steps to follow for each patient, an explanation of the content of the algorithm, and a detailed summary of the evidence base that underpins such advice. This third component will contain much of the nationally produced guideline. If made available in electronic format, these three components can be linked using hypertext, thus enabling users to look up the evidence base from the algorithm or prose summary, if appropriate.

I suspect that these three parts are, in essence, the key components of a useful clinical guideline listed by Jackson and Feder. However, a distinction between national and local production needs to be made explicit. Rigorously produced and appraised national guidelines will obviate the need for local practitioners to find and appraise the evidence, and they should be a template against which to achieve local agreement.

J G Williams Professor

School of Postgraduate Studies in Medical and

Health Care, Morriston Hospital, Swansea

SA6 6NL

john.g.williams@pgms.wales.nhs.uk

1 Jackson R, Feder G. Guidelines for clinical guidelines. BMJ 1998;317:427-8. (15 August)

2 Cluzeau F, Littlejohns P, Grimshaw J, Feder G. Appraisal instrument for clinical guidelines. Version 1. London: St George's Hospital Medical School, 1997.

3 Scottish Intercollegiate Guidelines Network. Helicobacter pylori. Eradication therapy in dyspeptic disease. A clinical guideline developed by a multi-professional expert group sponsored by the Clinical Resource and Audit Group (CRAG) and recommended for use in Scotland by the Scottish Intercollegiate Guidelines Network. Edinburgh: SIGN, 1996.

4 Grimshaw JM, Russell IT. Effect of clinical guidelines on medical practice. A systematic review of rigorous evaluations. Lancet 1993:342:1317-92.

\section{Guidelines in small countries and not translated into English may be ignored}

EDIToR-The fact that Wells can refer to seven meta-analyses of nine studies in breast cancer screening suggests that it may be too easy for anyone with a statistics program to do meta-analysis and, as a corollary, that some caution about the relevance of meta-analysis to everyday clinical practice is wise. ${ }^{1}$ Most $(60 \%)$ of the data on breast cancer screening discussed by Wells (her table 1) come from Sweden, a country of about nine million people; this is about $3 \%$ of the combined populations of the countries where the trials that she cites took place, which raises the issue of generalisability. Certainly, the Swedish studies took place in Sweden's three biggest cities and also in two counties, but the United Kingdom studies were based only in Edinburgh, not in London, Manchester, or Glasgow.

Although Wells specifically discusses events in the United States, it would have been useful to set this in the context of how Sweden has implemented the findings. I could find no reference to Swedish guidelines in her article. Perhaps they are available only in Swedish and are thus ignored, like the forgotten trial by Johannes Fibiger, which was published in Danish and is discussed by Hróbjartsson et al in the same issue of the $B M J .{ }^{2}$ Or was the process in Sweden hijacked by interest groups? Was the problem in the United States the fact that so many of the data originate from outside North America, which made it difficult to defend certain policies?

Lars Breimer Clinical research physician

13 Thornbury, Harpenden, Hertfordshire AL5 5SN

1 Wells J. Mammography and the politics of randomised controlled trials with commentary by $\mathrm{G}$ J Ong]. $B M J$ 1998;317:1224-30. (31 October.)

2 Hróbjartsson A, Gøtzsche PC, Gluud C. The controlled clinical trial turns 100 years: Fibiger's trial of serum treatment of diphtheria BMJ 1998:317:1243-5. (31 October.) 


\section{Inherited predisposition to hypertension confounds the effect of low birthweight}

EDITOR-Our study showed that the relation between lower birthweight and subsequent higher blood pressure in adulthood may be confounded by parental blood pressure. Mothers with higher blood pressure between 9 and 19 years after delivery had babies with lower birthweight who subsequently had higher blood pressure as adults.

Taylor et al seem to refute this finding by showing that maternal blood pressure measured during pregnancy did not confound the relation between lower birthweight and higher blood pressure in children aged 8-11 years. ${ }^{2}$ However, they have not acknowledged the weakness of measurement of maternal blood pressure in pregnancy. They do not cite a study showing that, although there is no relation between maternal blood pressure measured in the clinic during pregnancy and subsequent birthweight of the babies, an inverse relation is present across the range of normal blood pressures measured by ambulatory monitoring.. In addition, although there is an association between pregnancy induced hypertension and essential hypertension, the two conditions are not the same. Our measurement of blood pressure in non-pregnant women is not subject to the confounding influences affecting blood pressure during pregnancy and may therefore be considered to be a closer reflection of the predisposition to hypertension which children inherit from their mothers.

Further studies will be required to confirm or refute our observation, but Taylor et al have asked a different question, concerning pregnancy induced hypertension rather than inheritance of essential hypertension. Their negative result may reflect the imprecision of measurement of blood pressure during pregnancy.

Brian R Walker British Heart Foundation senior research fellow

University of Edinburgh, Department of Medicine Western General Hospital, Edinburgh EH4 2XU B.Walker@ed.ac.uk

\section{Graham CM Watt Professor}

University of Glasgow, Department of General Practice, Woodside Health Centre, Glasgow G20 7LR

1 Walker BR, McConnachie A, Noon JP, Webb DJ, Wat GCM. Contribution of parental blood pressures to association between birth weight and adult high blood pressure: cross sectional study. BMJ 1998;316:834-7. (14 March.)

2 Taylor SJC, Hird K, Whincup P, Cook D. Relation between birth weight and blood pressure is independent of maternal blood pressure. BMJ 1998;317:680. (5 September.)

3 Churchill D, Perry IJ, Beevers DG. Ambulatory blood pres

ure in pregnancy and fetal growth. Lancet 1997;349:7-10.

\section{Competency, consent, and the duty of care}

EDITOR-There seems to be another solution to the ethical dilemma posed by Inwald apart from those put forward by the commentators.

Inwald's patient had a long history of schizophrenia, with evidence of recent deterioration characterised by declining social and personal functioning and loss of insight into the consequences. This decline, possibly associated with a depressive illness after his mother's death, led to physical neglect. The patient therefore had the consequences of a mental illness under the terms of the Mental Health Act 1983.

The act states that people with mental illnesses can be formally admitted to hospital where this is necessary in the interests of their health or safety or for the protection of others. Only one of these categories needs to be satisfied-that is, patients can be admitted for assessment (section 2) or treatment (section 3) solely in the interests of their own health. The patient's physical as well as mental health was covered by this criterion. Inwald's statement that the patient was not "sectionable" under the Mental Health Act 1983 can therefore be challenged as the risk to physical health was secondary to mental illness.

Would compulsory admission to a psychiatric hospital have altered the ethical dilemma concerning surgical intervention for the patient's rectal prolapse? HippisleyCox and Hippisley-Cox ${ }^{1}$ are correct in asserting that the Mental Health Act has no role to play in the treatment of physical disability. One could argue, however, that with appropriate treatment of his mental illness, the patient's psychological condition may have improved sufficiently to have permitted him to make a more informed decision about the need for surgical intervention.

Ronan J McIvor Senior registrar in psychiatry National Hospital for Neurology and Neurosurgery, Queen Square, London WC1N 3BG

Inwald AC. Competency, consent, and the duty of care: Best of motives, worst of consequences. $B M$ 1998;317:809-10. [With commentaries by J Hippisley-Co and S Hippisley-Cox, and I Hill-Smith.] (19 September.) 2 Jones R. Mental health act manual, 5th ed. London: Sweet and Maxwell, 1996: 570-

\section{When big may not be beautiful}

EDITOR-Thank you for printing Markham's personal views, which are shared by this committee and the managers of this small geographically isolated trust.

We welcome change and innovation, and we work hard to provide excellent patient care. Because our service is mostly provided by consultants rather than led by them, we believe our service is often better than that supplied in the larger academic hospitals where doctors all received their training. We have foregone the distractions of the large private practices of metropolitan areas and rarely have the chance to sit on the prestigious committees that produce guidelines that insist that only the biggest can be the best-or the only "real" option for secondary medical care in the 21 st century.

We see a wide range of diseases, converse with colleagues on a broader range of topics than perhaps is possible in specialised localities with large impersonal numbers of senior staff, and, most important of all, we provide immediate health care to geographically isolated people.
We believe health services should be based first and foremost on our patients' needs rather than what the market place dictates. This includes referral to specialised units but not for every patient and not for every incident.

We are concerned that health authorities may be tempted to use the royal colleges' guidelines to help them respond to market forces and inadequate budgets. The resultant "cherry picking" of small specialties and the knock-on effect is potentially threatening to the survival of many small, isolated district general hospitals. We would urge colleagues to join us in asking the colleges to reconsider their views. This has proved possible at one formal college meeting since Markham's article was published, when mutually beneficial improvements were agreed. We would like to hear from others who share our views and will be happy to collate and coordinate responses to the colleges, the NHS Confederation, the Department of Health, and parliamentary representatives.

S G Barber Chairman medical staff committee A Bosley Paediatrician, small specialties group W Bradford Medical director

I Buchanan Maxillofacial surgeon

A Gibson Ophthalmologist small specialties group F O'Sullivan Chief executive

North Devon District Hospital, Raleigh Park, Barnstaple, Devon EX31 4JB 1 Markham N. When big may not be beautiful. BMJ
1998;317:1165. (October 24.)

\section{Fluoroquinolone resistance in salmonellas and campylobacters from humans}

EDITOR-In Piddock's editorial on fluoroquinolone resistance it was stated that Salmonella typhimurium with decreased susceptibility to fluoroquinolones and campylobacter resistant to fluoroquinolones have been isolated from animals and retail poultry. ${ }^{1}$ Unfortunately, information about the incidence of fluoroquinolone resistant $S$ typhimurium and campylobacter from human infections was not provided, nor was there any reference to underlying epidemiological events leading to the development of resistance.

The Laboratory of Enteric Pathogens is the national reference centre for salmonellas from humans in England and Wales. Since 1990 the most common serotypes have been $S$ enteritidis, $S$ typhimurium, $S$ virchow, and $S$ hadar. These are primarily zoonotic in origin, and the main food animal reservoirs are poultry, cattle, and pigs. In 1996, 702 of $5849(12 \%)$ isolates of S typhimurium were resistant to ciprofloxacin at $0.125 \mathrm{mg} / \mathrm{l}$, a 12 -fold increase since $1994 .^{2}$ Of particular importance has been the increasing occurrence of ciprofloxacin resistance in phage type 104 (DT104) already resistant to ampicillin, chloramphenicol, streptomycin, sulphonamides, and tetracyclines, with $12 \%$ of DT104 resistant to ciprofloxacin in 1996 and 1997. ${ }^{3}$ This increase is subsequent to the licensing in 
1993 of ciprofloxacin analogues for use in animal husbandry and is also reflected in food animals, with $78 \%$ of isolates of DT104 from turkeys, $31 \%$ from chickens, $11 \%$ from cattle, $5 \%$ from pigs, and $12 \%$ from sheep resistant to quinolones in $1997 .{ }^{4}$ Concern has been expressed about the therapeutic implications for humans of fluoroquinolone resistance in multiresistant DT104, and a lack of clinical response has recently been reported from Denmark in an outbreak of quinolone resistant DT104 associated with pork in which seven people were admitted to hospital-six were treated with fluoroquinolones and one died.

The Laboratory of Enteric Pathogens is also the national reference centre for campylobacter species from humans, and of 5800 isolates referred in 1996 and 1997, $12 \%$ were resistant to ciprofloxacin at $>8$ $\mathrm{mg} / \mathrm{l}$, and a further $4 \%$ had a ciprofloxacin minimum inhibitory concentration of 0.5 $\mathrm{mg} / \mathrm{l}$. Ciprofloxacin resistance was most pronounced in Campylobacter coli, with 22\% of isolates resistant.

The report from Denmark shows the clinical consequences for humans of the continuing use of fluoroquinolone antibiotics in food animals. A recent report by the House of Lords Select Committee on Science and Technology has recommended the rapid introduction of a code of practice on the use of fluoroquinolones in food animals. In light of the Danish experience, it is hoped that these recommendations will be rapidly implemented.

E J Threlfall Top grade microbiologist jthrelfall@phls.co.uk

J A Frost Principal grade microbiologist

B Rowe Consultant medical microbiologist

Laboratory of Enteric Pathogens, Central Public

Health Laboratory, London NW9 5HT

I Piddock LJV. Fluoroquinolone resistance. BMJ 1998; 317:1029-30.(17 October)

2 Threlfall EJ, Ward LR, Skinner JA, Rowe B. Increase in antibiotic resistance in nontyphoidal salmonellas from humans in England and Wales. Microb Drug Resis 1997;3:263-6

3 Threlfall EJ, Ward LR, Rowe B. Multiresistant Salmonella typhimurium DT104 and bacteraemia. Lancet 1998;352:287-8

4 Anon. Salmonella in livestock production, 1997. Ministry of Agriculture, Fisheries and Food, Welsh Office Agriculture Department, Scottish Office, Agriculture and Fisheries Department. Weybridge: Central Veterinary Laboratory, 1998.

5 Anon. Outbreak of quinolone-resistant Salmonella typhimurium DT 104 in Denmark. WHO Weekly Epidemiol Rec $1998 ; 42,327-8$

\section{Paediatric cardiac transplant surgery has improved}

EDITOR-Kelly and Mayer's editorial highlights current issues in paediatric transplantation. ${ }^{1}$ We think that the survival figures quoted for heart transplantation in children under the age of 6 are unduly pessimistic (60\% at two years-figures for 1992 cited); they do not reflect recent improvements in this group.

The intermediate results (two year actuarial survival) quoted for the American transplantation registry in 1996 for this group of patients was $75 \% .{ }^{2}$ A multi-institutional study confirmed these findings. ${ }^{3}$ Mitchell et al reported the outcome specifically for infants under 6 months and established actuarial survivals of $80 \%, 78 \%$ and $70 \%$ at one, two, and three years respectively in 51 consecutive patients. ${ }^{4}$ The Loma Linda group reports early mean actuarial survival of $80-90 \%$ and five year survival of $70-80 \%$.

In the past 11 years we have given transplants to 63 children under 16 with a median age at transplantation of 4.6 years. The actuarial survival at two years is $87 \%$ and at 10 years $82 \%$. The survival was not significantly different in children under and over 6 ( $85 \%$ and $90 \%$ respectively at two years).

These improved intermediate results reflect the experience gained in patient management in paediatric cardiac transplant surgery rather than altered selection criteria. It may be appropriate to consider transplantation rather than high risk palliative surgery for some patients with complex congenital heart disease. Achieving intermediate results comparable to those seen with adult cardiac transplantation has been encouraging.

C Wigfield Paediatric cardiac surgical fellow H C Leonard Specialist registrar paediatric cardiology

J R L Hamilton Consultant paediatric cardiac surgeon

A Hasan Consultant paediatric cardiac surgeon J H Dark Consultant in cardiothoracic surgery Freeman Hospital, Newcastle upon Tyne NE7 7DN xe106@dial.pipex.com (for Dr Wigfield)

1 Kelly D, Mayer AD. Paediatric transplantation comes of age. BMJ 1998;317:897. (3 December)

2 Hosenpud JD, Novick RJ, Bennett LE, Keck BM, Fiol B, Daily OP. The registry of the International Society for Heart and Lung Transplantation: thirteenth officia report-1996.J Heart Lung Transplant 1996;15:655-74.

3 Shaddy RE, Naftel DC, Kirklin JK, Boyle G, McGiffin DC Towbin JA, et al. Outcome of cardiac transplantation in children. Survival in a contemporary multi-institutiona experience. Circulation 1996;94(9 suppl):II69-73.

4 Mitchell MB, Campbell DN, Clarke DR, Fullerton DA, Grover FL, Boucet MM, et al. Infant heart transplantation: improved intermediate results. I Thorac Cardiovasc Sur 1998:116:242-52.

5 Bailey LL Graft vasculopathy among recipients of heart transplantation during the first 12 years of life. Transplan Proc 1995;27:1921-5.

\section{FDA approves drugs even} when experts on its advisory panels raise safety questions

EDITOR-After reading the editorial questioning whether the Food and Drug Administration is approving drugs too fast I was perplexed by the conclusion-"probably not." Apparently the authors failed to read the transcript of the meeting of the administration's advisory committee for mibefradil (NDA 20-689), which is on the administration's website-one of three drugs recently recalled by the administration because of deaths and serious morbidity.

If they had read this transcript they would have been overwhelmed by the number of disturbing signals from committee members throughout the document (page numbers refer to the Acrobat version) "I'm afraid that we are rushing into this" (p 199); "I think it's concerning that the mortality data look the way they do right now" (p 202); "given the fact that there are a lot of other effective therapies out there, why not be safe with the public?" (p 205); "I think it's premature [to approve the product] (p 209); “aren't we obligated to provide some assurance that the ECG (electrocardiographic) changes we've seen here today are not ultimately lethal?" (p 127); "I sure don't feel good about what I've seen" [referring to electrocardiographic changes] (p 126); "you have 8 deaths in the patients treated with mibefradil and 1 death in the placebo or control populations" ( $p$ 135); "are you really comfortable, with so little mortality data, ... that it's safe?" (p 138), etc.

To conclude, as the editorial does, that serious adverse events are inevitable and "one more bittersweet fact of medical progress" is too facile. A more plausible explanation recognises that, for some time, formidable forces-both political and economic-have insisted that new drugs and devices be approved more quickly than ever before by the administration. This interpretation agrees with the view held by many healthcare policy academics, patient advocate organisations, and consumer watchdog groups. They argue that in the past few years the Food and Drug Administration's role has changed. Rather than regulating the drug industry to protect the health of consumers of prescription drugs, the administration has become the industry's partner, rapidly approving drugs for marketing even when medical experts on its own advisory panels raise serious safety questions.

Although one may not entirely agree with this outlook, it does provide an explanation for much of the evidence that Kleinke and Gottlieb seem to have overlooked.

Laurence Landow Instructor in anesthesia, Harvard Medical School

Brigham and Women's Hospital, 75 Francis Street, Boston, MA 02115, USA

elmrfudd@erols.com

1 Kleinke JD, Gottlieb S. Is the FDA approving drugs too fast? BMJ 1998;317:899. (3 October.)

From 1996 to 1998 Dr Landow was a medical officer and acting team leader in the Anesthetic and Critical Care Drugs Section of the Center for Drug Evaluation and Research at the Food and Drug Administration.

\section{Oakley's case for using randomised controlled trials is misleading}

EDIToR-Oakley examines lessons in the history of the use of randomised controlled trials to evaluate social interventions. ${ }^{1}$ Her examination provides a misleading assessment of their usefulness in the evaluation of contemporary health promotion interventions. She suggests that randomised controlled trials are "ignored or regarded with suspicion" by the discipline of health promotion and that "experts ... have resisted the notion that rigorous evaluation of their work is more likely to give reliable answers than their own individual preferences." This is not the case, and in presenting case studies from American social experi- 
ments she does nothing to address the fundamental flaws in the application of randomised controlled trials to the evaluation of social interventions.

Three major issues have to be considered. The first concerns the unit of intervention. In all of Oakley's cases the study population comprises individuals or family units. In many contemporary social interventions, whole populations or subgroups in populations are the unit of intervention. Changes in risk in individuals are less important than change in the risk profile in populations.

Secondly, in all the examples provided the intervention is relatively simple and correspondingly simple to measure and control. Most contemporary health promotion programmes consist of multicomponent interventions, combining education and social mobilisation with policy and regulation. These interventions make use of social networks and the media. They are much less easy to measure and neatly separate for control purposes, and they require study designs that better reflect these complexities.

Thirdly, most social interventions require considerable time to produce measurable outcomes. Even if an experimental design was adopted, maintaining a separation between intervention and "control" populations over long periods is extremely difficult. Randomised controlled trials of simple and short term health promotion interventions are regularly undertaken, and the design is not ignored when it is appropriate.

The challenge of rigorous evaluation of more complex and sophisticated contemporary health promotion programmes is not being resisted. More appropriate research methods and outcome measures are being developed and applied. ${ }^{2}$

Don Nutbeam Professor of public health

Department of Public Health and Community

Medicine, University of Sydney, Sydney, NSW 2006, Australia

donn@pub.health.usyd.edu.au

Competing interests: None declared.

1 Oakley A. Experimentation and social interventions: a forgotten but important history. BMJ 1988;317:1239-42. (31 October.)

2 Nutbeam D. Evaluating health promotion: progress,

problems and solutions. Health Promotion Int 1998;23:27-44

\section{Needs of teenagers with chronic disability}

EDITOR-In Smith's editorial on the needs of teenagers with epilepsy, he states that "the consultation must focus on the needs and independence of the teenager, with the parents taking a back seat."1 This view replicates the individualistic approach of health education by treating teenagers as autonomous individuals, with little recognition of the constraints that might impact on choices.

In line with other work, ${ }^{2}$ my qualitative research on teenagers with either diabetes or asthma found that they tended to manage chronic disability in ways according to their sex (unpublished data). Teenage boys were more likely to try to hide any disability or to appear as being in control and unaffected by illness, particularly in public settings. Teenage girls, however, were happier to admit to having a chronic disability in both public and private settings.

In teenage boys, this minimising of disability in public was usually only possible because of the support they were given in managing their disease by their parentsalmost always mothers-at home. In contrast to the mothers of teenage girls, mothers of teenage boys were often very involved with the management of their sons' disability. Girls were much more likely to be independent in managing their disease-and often had been from an early age-and felt that this responsible behaviour was expected of them by others such as parents, teachers, and health professionals. This independence in management, however, did not always have positive effects for teenage girls. They were more likely than boys to be secretively non-compliant with aspects of their treatment regimens and to feel guilty because of this.

In terms of consultations, focusing on the needs of teenagers should mean listening to them in a non-judgemental way, with the recognition that young people are the experts in living with their chronic disability. What may be perceived as rebellious adolescent non-compliance may be teenagers skilfully adapting the regimen to fit in with their daily lives. If parents are present at consultations, it may be that they play a major role in helping the teenager to manage, and this could well be what the teenager has chosen. It should also be recognised that negative outcomes may result from promoting independence regardless and in encouraging parents to "take a back seat." Instead of independence, it may be more helpful to talk about interdependence, recognising that very few of us are completely independent, and that this may not be particularly desirable anyway.

Clare Williams Research fellow

Postgraduate Centre, United Medical and Dental Schools, St Thomas's Hospital, London SE1 7EH

1 Smith P. The teenager with epilepsy. BMJ 1998;317:960. (17 October.)

2 Moynihan C. Theories of masculinity. BMJ 1998;317:1072

\section{Cholesterol lowering diets and coronary heart disease}

\section{Diet alone substantially reduces} cholesterol in hypercholesterolaemia

EDITOR-In his letter Oliver states that "simple low fat and low cholesterol diets do not reduce plasma cholesterol concentration sufficiently to reduce the risk of coronary heart disease."1 Although this may be true of dietary advice offered to free-living communities-in which a $6 \%$ reduction in blood cholesterol concentrations is achieved $^{1}-$ it is not true of individual care and monitoring given by enthusiastic dietitians and physicians to well motivated subjects with hypercholesterolaemia. My colleagues and I found that such subjects, selected for their concern to improve their risk of coronary heart disease and therefore adjudged likely to benefit from the professional time and effort given to them and their spouses, achieved around a 22\% reduction in plasma cholesterol concentrations by diet alone. ${ }^{2}$

An encouraging feature of our study was that dietary preferences changed within a few months in favour of less fatty food. Long term adherence was also encouraged by our dietitians' skill in affording variety and culinary adventure within the healthier dietary regimen. As in other fields of endeavour, it's no good just being negative. The positive must be accentuated.

David W Evans Emeritus consultant cardiologist Addenbrooke's Hospital, Cambridge 27 Gough Way, Cambridge CB3 9LN

1 Oliver MF. Cholesterol lowering diets and coronary heart disease. BMJ 1998;317:1253. (31 October.)

2 Evans DW, Turner SM, Ghosh P. Feasibility of long-term plasma-cholesterol reduction by diet. Lancet 1972;i:172-4

\section{Farmed and wild fish may have different effects}

EDIToR-Oliver and Conway extol the benefits of eating fish to reduce the risk of coronary heart disease. ${ }^{12}$

Fish stocks are declining while the demand for fish worldwide is increasing. A major switch from red meat to fish (as already seen for poultry) will increase the pressure on natural fish stocks. As with poultry, the result will be intensive mass production by farming fish. George and I reviewed the literature to assess whether farmed fish have the same fatty composition as wild fish. ${ }^{3}$ We found seven studies in 1994. Although the evidence base is small and further research is needed, farmed and wild fish are different. In five studies farmed fish had a higher total fat content than wild fish. The ratio of $\mathrm{N}-3$ to $\mathrm{N}-6$ fatty acids was higher in wild trout, salmon, and carp in both of the studies that reported such data.

Fish farming poses both a threat and an opportunity. The threat is that the benefits promised by the results of studies of fish eating may not apply uniformly to farmed fish. The opportunity is that fish farmers can manipulate the diet of fish to optimise the fat composition for disease prevention. Epidemiologists, nutritionists, public health policy makers, and fish farmers need to confer.

Raj Bhopal Head

Department of Epidemiology and Public Health, University of Newcastle upon Tyne, Newcastle upon Tyne NE2 4HH

1 Oliver MF. Cholesterol lowering diets and coronary heart disease. BMJ 1998:317:1253. (31 October.)

2 Conway S. Cholesterol lowering diets and coronary heart disease $B M J 1998$ 317:1253. (31 Octs an

- Geore R, Bhopal R. Fat composition of free living and George R, Bhopal R. Fat composition of free living and farmed sea species: implications for human diet and sea-farming techniques. British Food Journal 1995;97:
19-22.

\section{Rapid responses} eBM

Rapid responses submitted directly to our website are available on www.bmj.com 